Article

\title{
Rapid Sequentially Palladium Catalyzed Four-Component Synthesis of Novel Fluorescent Biaryl-Substituted Isoxazoles
}

\author{
Tobias Deden ${ }^{1}$, Lars May ${ }^{1}$, Guido J. Reiss ${ }^{2}$ and Thomas J. J. Müller ${ }^{1, *}$ \\ 1 Institut für Organische Chemie und Makromolekulare Chemie, Heinrich-Heine-Universität Düsseldorf, \\ Universitätsstraße 1, D-40225 Düsseldorf, Germany; Tobias.Deden@hhu.de (T.D.); \\ Lars.May@uni-duesseldorf.de (L.M.) \\ 2 Institut für Anorganische Chemie und Strukturchemie, Heinrich-Heine-Universität Düsseldorf, \\ Universitätsstraße 1, D-40225 Düsseldorf, Germany; Guido.Reiss@uni-duesseldorf.de \\ * Correspondence: ThomasJJMueller@uni-duesseldorf.de; Tel.: +49-211-81-12298
}

Received: 5 November 2020; Accepted: 30 November 2020; Published: 3 December 2020

\begin{abstract}
A series of novel 3- and 5-biaryl-substituted isoxazoles was prepared by a rapid microwave-assisted four-component three-step synthesis: concatenating Sonogashira coupling, cyclocondensation, and Suzuki coupling in a one-pot fashion. The Pd-catalyst was successfully employed in the sense of a sequentially catalyzed process, i.e., without the addition of further catalyst loading. Biaryl-substituted isoxazoles with donor-acceptor decoration possess remarkable photophysical properties, such as high fluorescence quantum yields in solution up to $\Phi_{\mathrm{F}}=0.86$ and large Stokes shifts up to $10,000 \mathrm{~cm}^{-1}$. The experimental absorption and emission characteristics can be reproduced and rationalized by computations on the DFT (density functional theory) and TDDFT (time-dependent density functional theory) level of theory.
\end{abstract}

Keywords: absorption; catalysis; DFT calculations; fluorescence; isoxazoles; multicomponent reactions; sequential catalysis

\section{Introduction}

Isoxazole, although scarcely found in nature, is an important aromatic heterocycle with considerable biological activity. For instance, isoxazole derivatives exhibit anti-inflammatory [1,2], anti-microbial [3,4], anti-viral [5], or anti-cancerogenic [6,7] profiles. Furthermore, isoxazoles are also found in neuropsychiatric therapy [8] and in crop protection [9]. Surprisingly, their photophysical properties have remained largely unexplored [10-12].

Isoxazole syntheses have been known for a long time, and various approaches to the formation of the isoxazole core can be found in the literature [13,14]. In the past decade alone, multicomponent reactions (MCR) of isoxazoles as one-pot accesses were reported for 3,5-disubstituted isoxazoles [15-18], 4-acyl-3,5-disubstituted isoxazoles [19], and 3,4,5-trisubstituted isoxazoles [20,21]. Surprisingly, isoxazoles with biphenyl substituents are scarcely found. Because of the biphenyl twist in the electronic ground state $\mathrm{S}_{0}\left(\theta \sim 34^{\circ}\right)$, which transforms into coplanarity after photonic excitation and vibrational relaxation to $S_{1}$, a favorable property of fluorescent chemosensors with large Stokes shifts can be derived [22-24]. Therefore, we envisioned an MCR approach to biaryl-substituted isoxazoles, enabling the design of functional $\pi$-systems based on diversity-oriented synthesis [25-27]. Inspired by our four-component synthesis of biaryl-substituted pyrazoles [28], we assumed that a sequentially Pd-catalyzed process can be transposed to the MCR formation of biarylated isoxazoles. Sequential catalysis is a particularly attractive concept, featuring multiple uses of an initially employed catalyst for a subsequent reaction step [29-31]. In line with the advantages of MCR, the catalyst is also 
used economically and effectively. Our retrosynthetic analysis of biaryl-substituted isoxazoles is based on the ynone approach [32], employing acid chloride and alkyne for ynone formation via Sonogashira coupling, followed by cyclocondensation with hydroxyl amine and concluded by Suzuki-Miyaura coupling in a one-pot fashion, i.e., a coupling-cyclocondensation-coupling $\left(\mathrm{C}^{3}\right)$ sequence (Scheme 1).
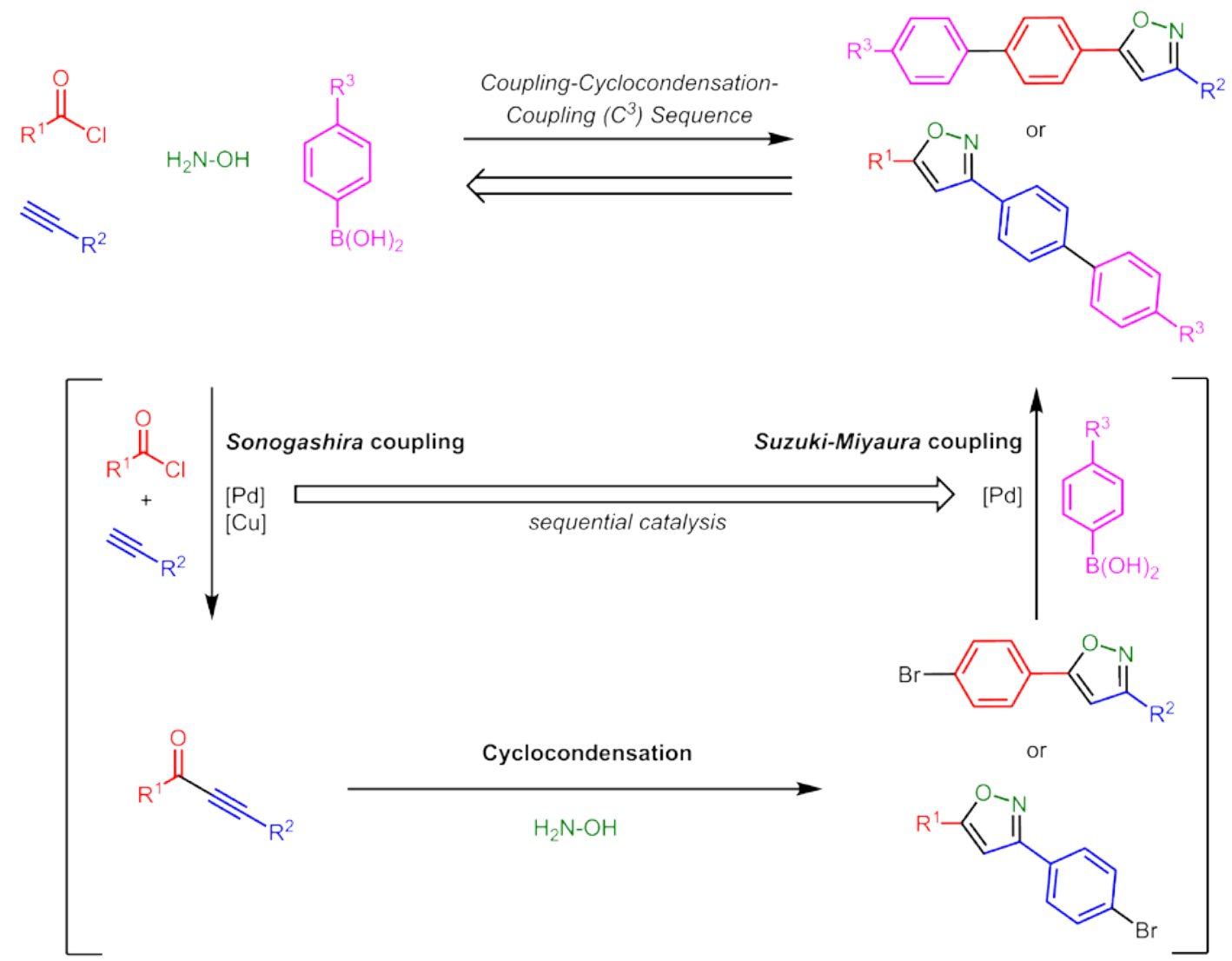

Scheme 1. Retrosynthetic analysis of biaryl-substituted isoxazoles via coupling-cyclocondensationcoupling $\left(\mathrm{C}^{3}\right)$ one-pot methodology including sequential use of the Pd catalyst.

Here, we report a novel sequentially Pd-catalyzed one-pot synthesis of biaryl-substituted isoxazoles in a consecutive four-component fashion. Furthermore, by a suitable donor-acceptor substitution enhancing the emission characteristics, the photonic properties are investigated by UV/vis and fluorescence spectroscopy, as well as by DFT (density functional theory) and TDDFT (time-dependent density functional theory) studies to rationalize the electronic structure.

\section{Results and Discussion}

\subsection{Synthesis and Structure}

Biaryl-substituted isoxazoles, as their pyrazole congeners [28], might be best accessible by catalytic ynone formation [32], with bromine containing aroyl chlorides or alkynes, setting two points of diversity in this type of level-two functionalization. The isoxazole core itself forms by regioselective Michael addition-cyclocondensation [18]. For the one-pot synthesis of 3-biaryl-substituted isoxazoles, we set out with a Pd-catalyzed Sonogashira coupling of an aroyl chloride $\mathbf{1}$ with $p$-bromophenyl acetylene (2a). After formation of the corresponding alkynone (monitored by TLC), the subsequent cyclocondensation with hydroxylamine was rapidly performed in the microwave reactor followed by Suzuki coupling of various boronic acids 3, without further addition of Pd catalysts to the reaction mixture (Scheme 2). The desired 3-biaryl-substituted isoxazoles 4 were isolated in moderate to very good yields for the overall reaction sequence of this four-component synthesis in less than $2 \mathrm{~h}$ (Table 1). 
The structures of compounds 4 were unambiguously assigned by ${ }^{1} \mathrm{H}$ and ${ }^{13} \mathrm{C}$ NMR spectroscopy and mass spectrometry.

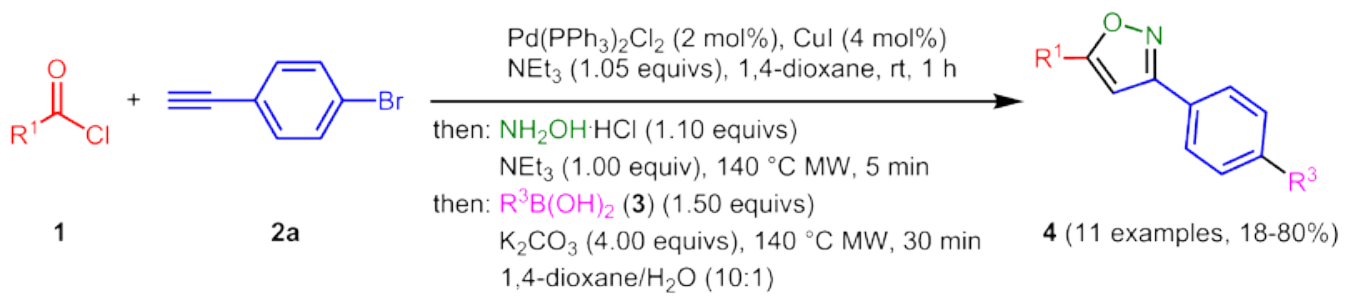

Scheme 2. Consecutive coupling-condensation-coupling $\left(\mathrm{C}^{3}\right)$ synthesis of 3-biaryl-substituted isoxazoles 4 .

Assuming that four new bonds are being formed in the sequence, the average yield per bond-forming step accounts for 65-95\%. Aroyl chlorides with halogen substituents (Table 1, entries 3-5) or strongly electron donating and withdrawing boronic acids, such as $\mathbf{3} \mathbf{d}$ and $\mathbf{3 f}$ (Table 1, entries 8 and 10), give considerably lower yields after isolation by chromatography. However, in principle, both electron-rich (Table 1, entries 2, 6, 8) and electron-poor substituents (Table 1, entries 3-5, 7, 9) can be present on both aryl rings of the isoxazole. The introduction of an aldehyde functionality (Table 1, entry 9) opens up possibilities for further functionalization. A donor-acceptor conjugate with a methoxy and a nitrile substituent can be readily established (Table 1, entry 11).

Table 1. 3-Biaryl-substituted isoxazoles 4 by four-component coupling-condensation-coupling $\left(C^{3}\right)$ synthesis.

Entry $\quad$ Acid Chloride 12 Boronic Acid 3
$\mathrm{R}^{1}=\mathrm{Ph}(\mathbf{1} \mathbf{a})$
$\mathrm{R}^{1}=p-\mathrm{MeOC}_{6} \mathrm{H}_{4}(\mathbf{1 b})$
$\mathrm{R}^{1}=0-\mathrm{FC}_{6} \mathrm{H}_{4}(\mathbf{1})$


Catalysts 2020, 10, 1412

4 of 16

Table 1. Cont.

Entry

Acid Chloride 1

Boronic Acid 3

4

$$
\mathrm{R}^{1}=p-\mathrm{F}_{3} \mathrm{CC}_{6} \mathrm{H}_{4}(\mathbf{1 d})
$$

$3 a$
3-Biaryl-substituted Isoxazoles 4<smiles>Cc1ccc(-c2ccc(-c3cc(-c4ccc(C(F)(F)F)cc4)on3)cc2)cc1</smiles>

4d (25\%)<smiles>Cc1ccc(-c2ccc(-c3cc(-c4cccc(Cl)c4)on3)cc2)cc1</smiles><smiles>CCCCCCCOc1ccc(-c2ccc(-c3cc(-c4ccccc4)on3)cc2)cc1</smiles>

(74\%)<smiles>C[N+]([Na])c1ccc(-c2ccc(-c3cc(-c4ccccc4)on3)cc2)cc1</smiles>

$(71 \%)$<smiles>CN(C)c1ccc(-c2ccc(-c3cc(-c4ccccc4)on3)cc2)cc1</smiles>

(27\%)<smiles>O=Cc1ccc(-c2ccc(-c3cc(-c4ccccc4)on3)cc2)cc1</smiles>

$(53 \%)$ 
Table 1. Cont.

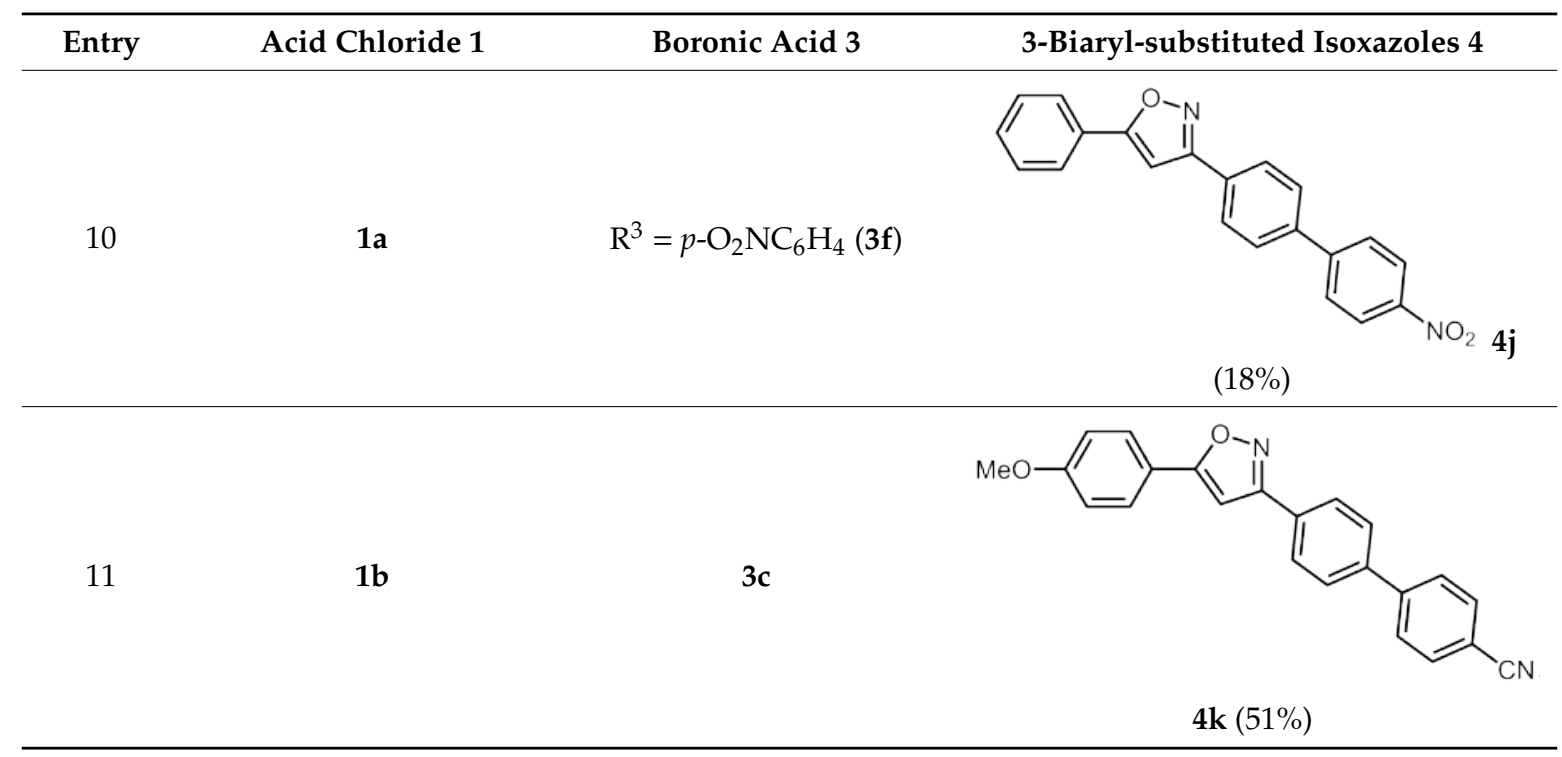

For compound $4 \mathbf{k}$, the molecular structure was additionally corroborated by single crystal structure analysis (Figure 1) [33]. The torsion angles $\theta$ of the four ring planes account for $13.2^{\circ}$ for $\mathrm{C}(5)-\mathrm{C}(4)-\mathrm{C}(7)-\mathrm{C}(8)$ ( $p$-anisyl ring vs. isoxazole), $-11.1^{\circ}$ for $\mathrm{C}(8)-\mathrm{C}(9)-\mathrm{C}(10)-\mathrm{C}(15)$ (isoxazole vs. central $p$-phenylene), and $-4.8^{\circ}$ for $\mathrm{C}(14)-\mathrm{C}(13)-\mathrm{C}(16)-\mathrm{C}(21)$ (central $p$-phenylene vs. $p$-cyanophenyl) and indicate an almost coplanarily arranged geometry in the solid state.

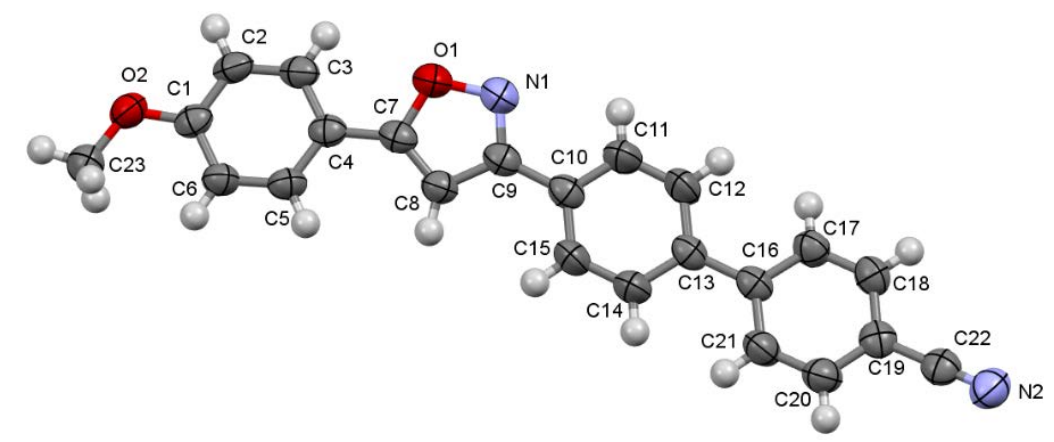

Figure 1. Molecular structure of compound 4k (thermal ellipsoids shown at 50\% probability).

The packing of isoxazole $4 \mathbf{k}$ was analyzed by a quantitative analysis of intermolecular interactions with Hirshfeld surfaces using the program CrystalExplorer [34] following a specific methodology [35-37]. The Hirshfeld surface $\left(\mathrm{d}_{\text {norm }}\right.$, Figure 2$)$ displays close intermolecular contacts (red circles on the $\mathrm{d}_{\text {norm }}$ surface) from the nitrile nitrogen atom N2 to the hydrogen atom of $\mathrm{C} 2$ and the hydrogen atom of $\mathrm{C} 18$, as well as between the methoxy oxygen atom $\mathrm{O} 2$ and the methyl hydrogen atoms of $\mathrm{C} 23$. The majority of the surface is white or blue, representing the sum or longer than van-der-Waals contact distances, especially between molecules that are stacked side by side (Figure 2).

The synthesis of 5-biaryl-substituted isoxazoles was likewise performed employing $p$-bromobenzoyl chloride (1f) as a substrate (Scheme 3, Table 2). For this series, the yields after chromatography are considerably lower, and the targeted 5-biaryl-substituted isoxazoles 5 are obtained in $6-49 \%$ yield. However, three particularly photophysically interesting donor-acceptor decorated 5-biaryl-substituted isoxazoles were prepared (Table 2, entries 3-5). The structures of compounds 5 were unambiguously assigned by ${ }^{1} \mathrm{H}$ and ${ }^{13} \mathrm{C}$ NMR spectroscopy and mass spectrometry. 


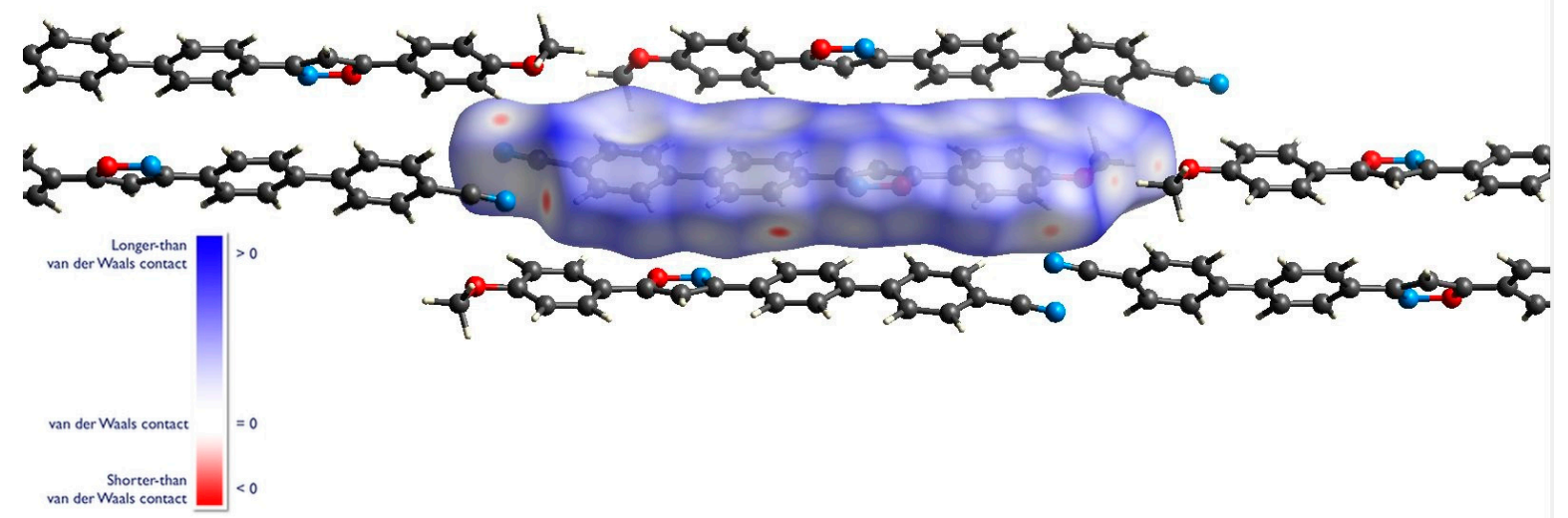

Figure 2. Hirshfeld surface of isoxazole $4 \mathbf{k}$ in the crystal lattice mapped with the $\mathrm{d}_{\text {norm }}$ property [37]. Red represents the closest, blue the most distant contacts.

Table 2. 5-Biaryl-substituted isoxazoles 5 by four-component coupling-condensation-coupling $\left(\mathrm{C}^{3}\right)$ synthesis.

Entry Alkyne 2



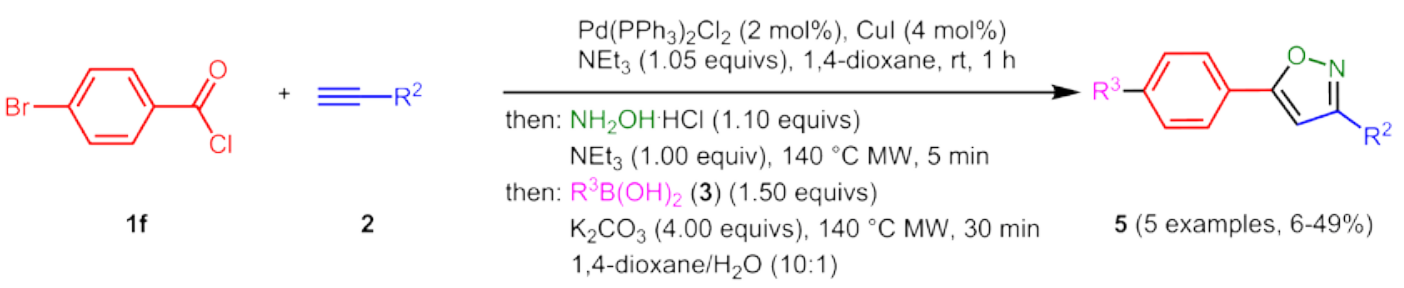

Scheme 3. Consecutive coupling-condensation-coupling $\left(\mathrm{C}^{3}\right)$ synthesis of 5-biaryl-substituted isoxazoles 5 .

Most conveniently, the regioselectivity of isoxazoles is determined by EI (electron ionization) mass spectrometry as illustrated for the regioisomeric compounds $\mathbf{4 a}$ and $\mathbf{5 a}$ (Figure 3). Fragmentation of the isoxazole ring generally produces the corresponding acyl cation as a base fragment, displaying a high intensity in the EI mass spectrum. In comparison, fragment $\mathrm{m} / \mathrm{z}=105$ is clearly detectable for compound $\mathbf{4 a}$, while $m / z=195$ is only found in the EI mass spectrum of regioisomer $\mathbf{5 a}$.

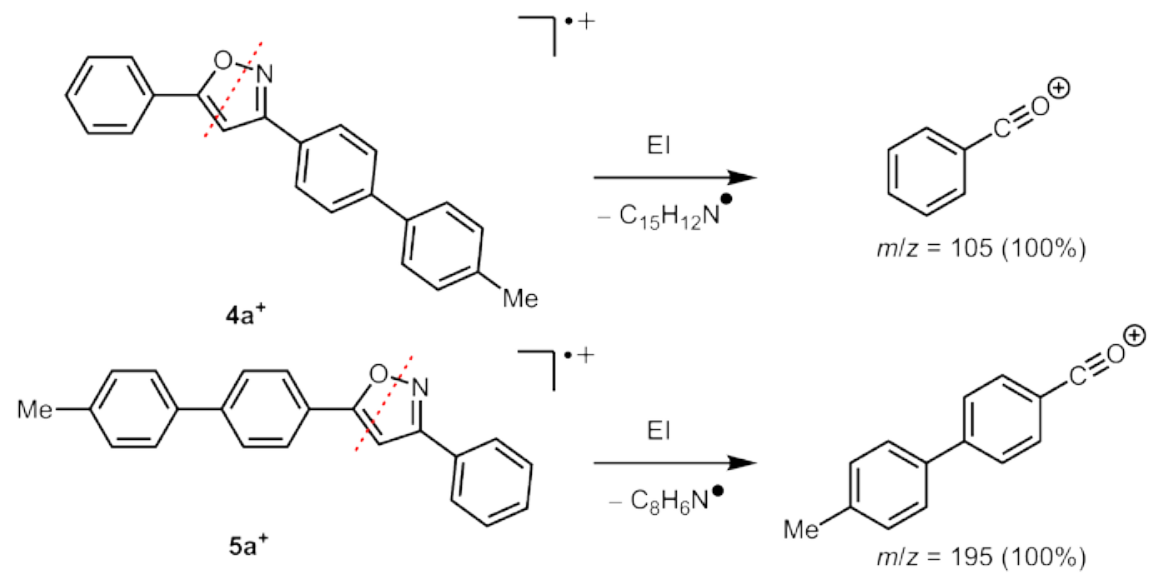

Figure 3. Determination of regioisomers by EI (electron ionization) mass spectrometry (relative intensity in parentheses).

\subsection{Photophysical Properties}

Compounds $\mathbf{4 k}, \mathbf{5 c}, \mathbf{5 d}$, and $\mathbf{5 e}$ are distinctive push-pull systems and fluoresce strongly in solution already visible to the unaided eye. Therefore, the photophysical properties were thoroughly investigated by UV/vis and static fluorescence spectroscopy in solution (Figure 4, Table 3). Compound $\mathbf{4 k}$ is the only representative in this series bearing a biaryl substituent in 3-position and shows the most hypsochromically shifted absorption maximum at $294 \mathrm{~nm}$ with the highest molecular absorption coefficient $\varepsilon\left(66,000 \mathrm{M}^{-1} \mathrm{~cm}^{-1}\right)$. The emission maximum of $4 \mathrm{k}$ appears at $423 \mathrm{~nm}$, giving the largest Stokes shift in this series $\left(10,400 \mathrm{~cm}^{-1}\right)$. On the other hand, the fluorescence quantum yield $\Phi_{\mathrm{F}}=0.17$ is rather low. While the absorption maxima of compounds $\mathbf{5 c}$ and $\mathbf{5 d}$ are identical and appear at $311 \mathrm{~nm}\left(\varepsilon=40,000\right.$ and $45,100 \mathrm{~m}^{-1} \mathrm{~cm}^{-1}$, resp.), compound 5e shows a large bathochromic shift to $356 \mathrm{~nm}\left(\varepsilon=34,100 \mathrm{~m}^{-1} \mathrm{~cm}^{-1}\right)$. The emission maximum of derivative $5 \mathrm{~d}(411 \mathrm{~nm})$ is bathochromically shifted in comparison to isoxazole $5 \mathrm{c}(376 \mathrm{~nm})$, which implies the electronic influence of the stronger electron-withdrawing cyano substituent in comparison to the trifluoromethyl substituent. Beyond this, the introduction of the strong dimethylamino donor in compound $\mathbf{5 e}$ leads to a large bathochromic shift of the emission maximum to $554 \mathrm{~nm}$. The resulting Stokes shifts for the consanguineous series of compounds $\mathbf{5 c}, \mathbf{5 d}$, and $\mathbf{5 e}$ are 5600,7800 and $10,000 \mathrm{~cm}^{-1}$ and the fluorescence quantum yields are considerably high at $\Phi_{\mathrm{F}}=0.86(5 \mathrm{c}), \Phi_{\mathrm{F}}=0.62(5 \mathrm{~d})$ and $\Phi_{\mathrm{F}}=0.69(5 \mathbf{e})$. 


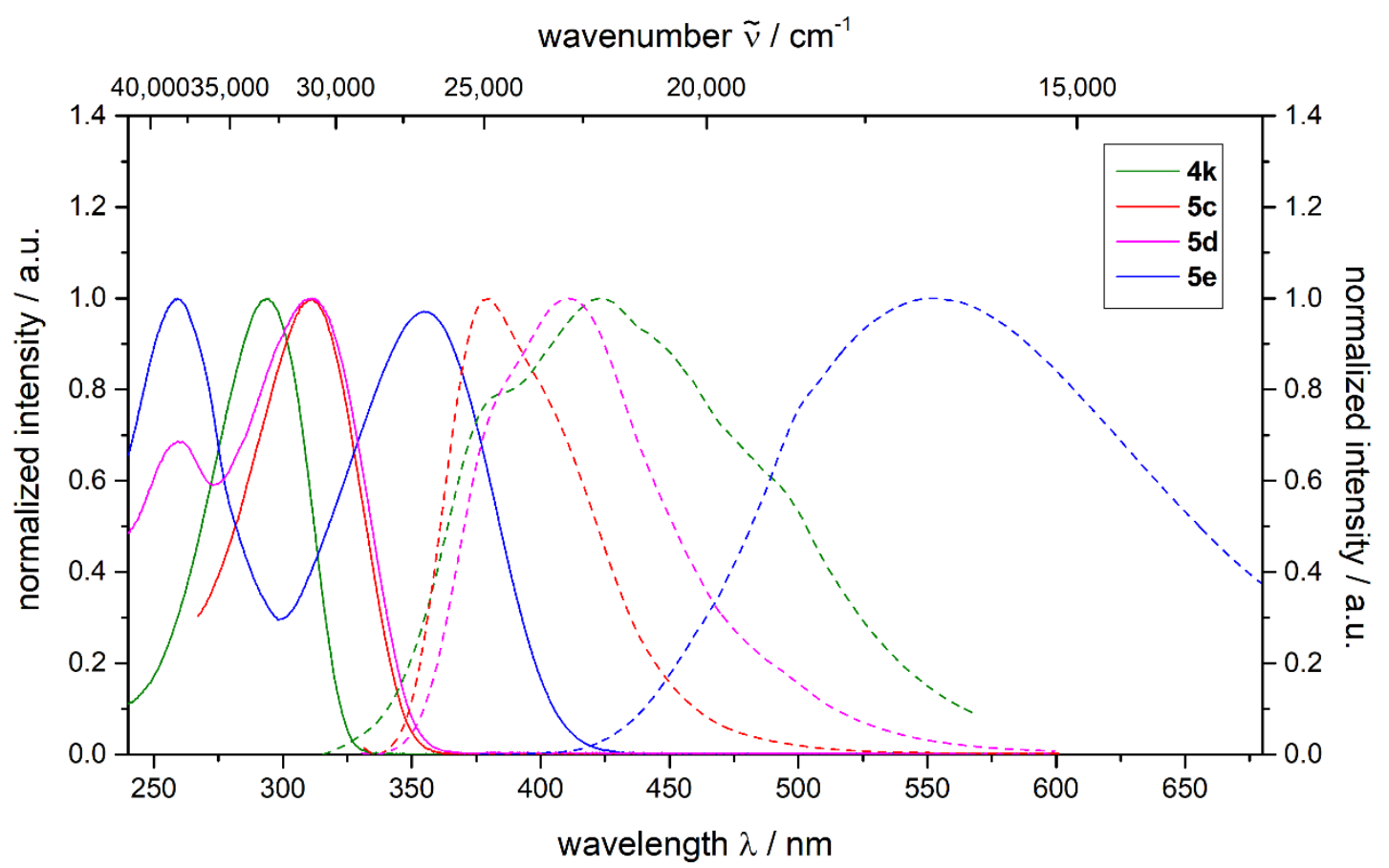

Figure 4. Normalized absorption (solid line) and emission (dashed line) spectra of biaryl-substituted isoxazoles $\mathbf{4 k}, \mathbf{5 c}$, 5d, and $\mathbf{5 e}$ (recorded in $\mathrm{CH}_{2} \mathrm{Cl}_{2}$ at $293 \mathrm{~K}, \lambda_{\text {exc }}=\lambda_{\text {max }, a b s}$ ).

Table 3. Selected photophysical properties of biaryl-substituted isoxazoles $\mathbf{4 k}, \mathbf{5 c}, \mathbf{5 d}$, and $\mathbf{5 e}$ (recorded in $\mathrm{CH}_{2} \mathrm{Cl}_{2}$ at $\left.293 \mathrm{~K}\right)$.

\begin{tabular}{cccc}
\hline Compound & $\begin{array}{c}\text { Absorption Maxima } \\
\lambda_{\text {max,abs }}(\mathbf{n m})\left(\varepsilon\left(\mathbf{M}^{-\mathbf{1}} \mathbf{c m}^{-\mathbf{1}}\right)\right)\end{array}$ & $\begin{array}{c}\text { Emission Maxima } \\
\lambda_{\text {max,em }}(\mathbf{n m})\left(\boldsymbol{\Phi}_{F}\right)\end{array}$ & $\begin{array}{c}\text { Stokes Shift a } \\
\boldsymbol{\Delta} \widetilde{v}\left(\mathbf{c m}^{\mathbf{- 1}}\right)\end{array}$ \\
\hline $\mathbf{4 k}$ & $294(66,000)$ & $423(0.17)^{\mathrm{b}}$ & 10,400 \\
\hline $\mathbf{5 c}$ & $311(40,000)$ & $376(0.86)^{\mathrm{b}}$ & 5600 \\
\hline $\mathbf{5 d}$ & $311(45,100)$ & $411(0.62)^{\mathrm{b}}$ & 7800 \\
\hline $\mathbf{5}$ & $356(34,100)$ & $554(0.69)^{\mathrm{c}}$ & 10,000 \\
\hline
\end{tabular}

${ }^{a}$ Stokes shift $\Delta \widetilde{v}=1 / \lambda_{\text {max,abs }}-1 / \lambda_{\text {max,em }}\left(\mathrm{cm}^{-1}\right) .{ }^{\mathrm{b}}$ Quantum yield $\Phi_{F}$ was determined in toluene $(4 \mathbf{k}), \mathrm{CH}_{2} \mathrm{Cl}_{2}(\mathbf{5 c})$ or THF (tetrahydrofuran) (5d) with 2,5-diphenyloxazole as a standard in methanol $\left(\Phi_{F}=0.86\right)$ [38], $\lambda_{\mathrm{exc}}=280$ nm. ${ }^{\mathrm{c}}$ Quantum yield $\Phi_{F}$ was determined in toluene with coumarin 1 as a standard in ethanol $\left(\Phi_{F}=0.73\right)$ [39], $\lambda_{\mathrm{exc}}=373 \mathrm{~nm}$.

In contrast to the strongest push-pull chromophore $5 \mathbf{e}$, the biaryl-substituted isoxazoles $\mathbf{5 c}$ and $\mathbf{5 d}$ are reasonably soluble in solvents covering a broader polarity range. Measurements of the corresponding fluorescence maxima and relative emission intensity, in comparison to the intensity in toluene, reveal that the emission maxima redshift from toluene $\left(5 \mathrm{c}: \lambda_{\max , e m}=373 \mathrm{~nm}\right.$, rel. intensity 1.00; 5d: $\lambda_{\max , e m}=372 \mathrm{~nm}$, rel. intensity 1.00) over dichloromethane (5c: $\lambda_{\max , e m}=376 \mathrm{~nm}$, rel. intensity 0.92; 5d: $\lambda_{\max , e m}=411 \mathrm{~nm}$, rel. intensity 0.25$)$ to acetonitrile $\left(5 \mathrm{c}: \lambda_{\max , e m}=407 \mathrm{~nm}\right.$, rel. intensity 0.59 ; $5 \mathrm{~d}: \lambda_{\max , e m}=498 \mathrm{~nm}$, rel. intensity 0.16 ) with concomitant attenuation of the emission intensity with increased polarity (for details, see Supplementary Materials, Table S3 (Solvent-dependent emission of compounds $\mathbf{5 c}$ and $\mathbf{5 d}$ (recorded at $293 \mathrm{~K}, c_{0}(5)=10^{-6} \mathrm{M}, \lambda_{\text {exc }}=\lambda_{\text {max,abs }}$ )), Figure $\mathrm{S} 1$ (Normalized emission spectra of $5 \mathrm{c}$ in toluene, $\mathrm{CH}_{2} \mathrm{Cl}_{2}$ and $\mathrm{MeCN}$ (recorded at $293 \mathrm{~K}, \lambda_{\mathrm{exc}}=\lambda_{\text {max,abs }}$ )) and Figure S2 (Normalized emission spectra of $\mathbf{5 d}$ in toluene, $\mathrm{CH}_{2} \mathrm{Cl}_{2}$ and $\mathrm{MeCN}$ (recorded at $\left.293 \mathrm{~K}, \lambda_{\mathrm{exc}}=\lambda_{\max , \text { abs }}\right)$ )). Since specific interactions such as hydrogen bonding are absent, this steady diminution of fluorescence intensity with increasing redshift of the emission band is in full agreement with the energy gap law [40].

Compound $4 \mathbf{k}$ also shows fluorescence in a solid state that is visible to the unaided eye. Therefore, isoxazoles $\mathbf{4 k}, \mathbf{5 c}$, $\mathbf{5 d}$ and $\mathbf{5 e}$ were additionally investigated by solid-state fluorescence 
spectroscopy (Figure 5, Table 4). All compounds show measurable fluorescence, although the fluorescence quantum yields of $\mathbf{5 c}, \mathbf{d}$ are only minor. The emission maxima follow the same trend as in solution with $5 \mathbf{c}$ showing the most blue-shifted emission at $391 \mathrm{~nm}$, followed by $5 \mathbf{d}(405 \mathrm{~nm})$, $4 \mathbf{k}(448 \mathrm{~nm})$, and $\mathbf{5 d}$ with the most redshifted emission maximum at $508 \mathrm{~nm}$.

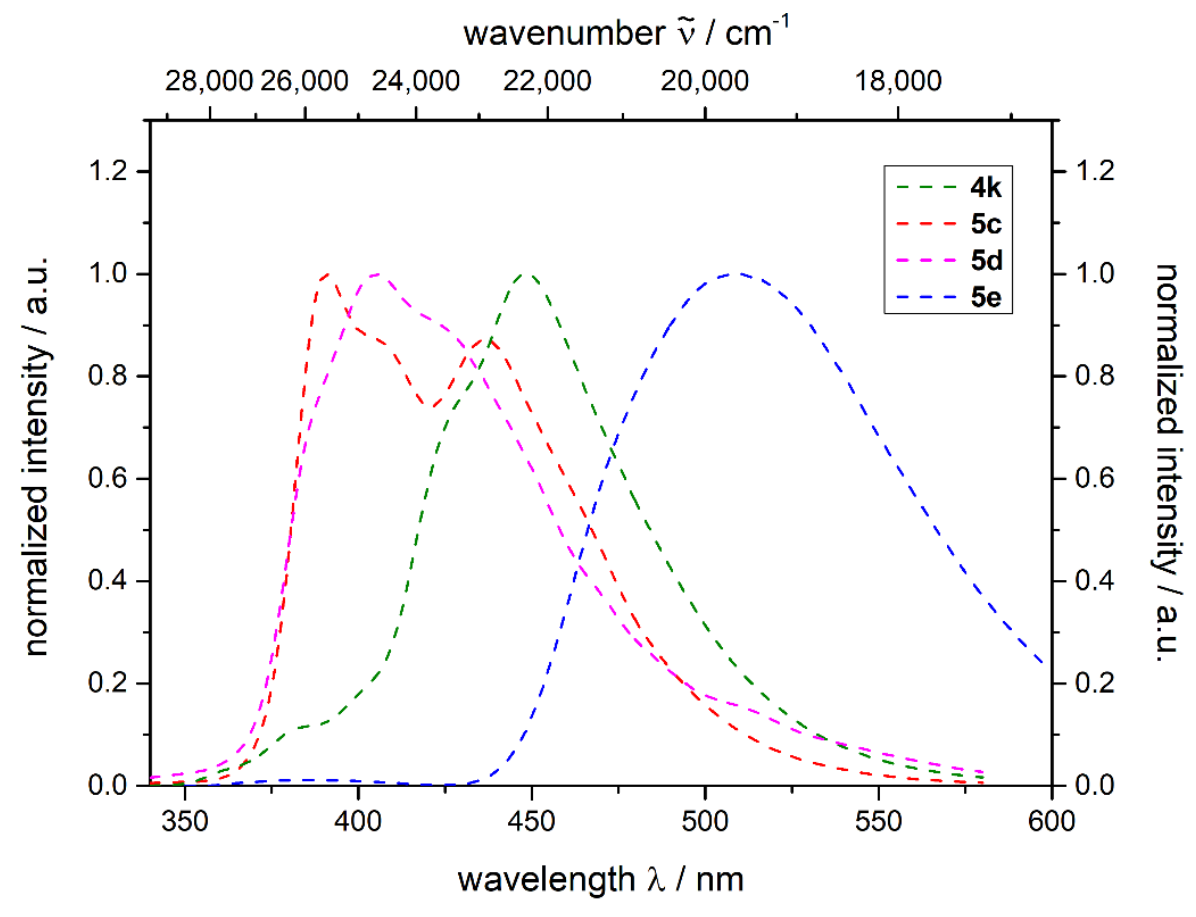

Figure 5. Normalized solid-state emission spectra of biaryl-substituted isoxazoles $4 \mathbf{k}, \mathbf{5 c}$, $5 \mathbf{d}$, and $\mathbf{5 e}$ $\left(\lambda_{\text {exc }}=300\right.$ or $330 \mathrm{~nm}$, recorded at $\left.293 \mathrm{~K}\right)$.

Table 4. Solid-state emission maxima of $4 \mathbf{k}, \mathbf{5 c}$, 5d, and $5 \mathbf{e}$ (recorded at $293 \mathrm{~K}$ ).

\begin{tabular}{cc}
\hline Compound & Emission Maxima $\lambda_{\text {max,em }}(\mathbf{n m})\left(\Phi_{F}\right)$ \\
\hline $\mathbf{4 k}$ & $448(0.07)^{\mathrm{a}}$ \\
\hline $\mathbf{5 c}$ & $391(<0.01)^{\mathrm{a}}$ \\
\hline $\mathbf{5 d}$ & $405(<0.01)^{\mathrm{a}}$ \\
\hline $\mathbf{5 e}$ & $508(<0.01)^{\mathrm{b}}$ \\
\hline & ${ }^{\mathrm{a}} \lambda_{\mathrm{exc}}=300 \mathrm{~nm},{ }^{\mathrm{b}} \lambda_{\mathrm{exc}}=330 \mathrm{~nm}$.
\end{tabular}

Within the consanguineous series of isoxazoles $\mathbf{5 c}$, $\mathbf{5 d}$, and $\mathbf{5 e}$, the photophysical properties generally follow the expected trend in accordance with the electronic nature of their substituents. However, the properties of isoxazole $\mathbf{4 k}$ clearly stand out. Compared to isomer $\mathbf{5 d}$, changing the biphenyl positioning from the 5-position to the 3-position causes a hypsochromic shift of the absorption band, and a bathochromic shift of the emission band of compound 4k. Simultaneously, the fluorescence quantum yield drops from $0.62(5 \mathbf{d})$ to $0.17(4 \mathbf{k})$. Although different solvents were employed for determining the fluorescence quantum yield, further experiments clearly showed that the polarity of the solvent is not solely responsible for the differences in the quantum yields.

\subsection{Computational Studies and Electronic Structure}

A deeper understanding of the electronic structure of compounds $4 \mathbf{k}, \mathbf{5 c}, \mathbf{5 d}$, and $\mathbf{5 e}$ was sought by DFT calculations using Gaussian09 [41]. The ground state geometries were optimized using the B3LYP functional [42-46] with the Pople 6-311G(d,p) basis set [47] applying the polarizable continuum model (PCM) [48] with dichloromethane as a solvent. The DFT optimized structures were confirmed as local minima by frequency analyses. 
Based upon the crystal structure of compound 4k (vide supra), a closer look was taken at the conjugation of the $\pi$-electron system, comparing the computed torsion angles of isomers $4 \mathbf{k}$ and $\mathbf{5 d}$ in solution and of $\mathbf{4 k}$ in the solid state (Table 5). Expectedly, in solution angle $\gamma$ of the biphenyl torsion of $\sim 35^{\circ}$ becomes apparent [49]. In the crystal structure of compound $4 \mathbf{k}$, this torsional angle only amounts to $4.8^{\circ}$. The other torsional angles (around the isoxazole core) fall cum grano salis in the same margin. With regard to the crystal structure, it can be stated that the remarkably low biphenyl torsion angle in the crystal is probably a consequence of the observed packing effects.

Table 5. Comparison of computed torsion angles between isoxazoles $4 \mathbf{k}$ and $\mathbf{5 d}(\mathrm{B} 3 \mathrm{LYP} / 6-311 \mathrm{G}(\mathrm{d}, \mathrm{p})$; polarizable continuum model (PCM): $\mathrm{CH}_{2} \mathrm{Cl}_{2}$ ).

Torsional Angle $\alpha$ Torsional Angle $\beta$ Torsional Angle $\gamma$

Additionally, TD-DFT [50-52] calculations were employed to compute the absorption maxima for these compounds (CAM-B3LYP functional [53]; 6-311++G(d,p) basis set; PCM: dichloromethane). In general, the computed values for the absorption maxima are in good agreement with the experiment (Table 6). Only derivative 5e shows an even stronger bathochromic shift in the absorption maximum $(356 \mathrm{~nm})$ than predicted by the calculation $(333 \mathrm{~nm})$.

Table 6. Experimental (recorded in $\mathrm{CH}_{2} \mathrm{Cl}_{2}$ at $293 \mathrm{~K}$ ) and TDDFT (time-dependent density functional theory) calculated of the absorption maxima of isoxazoles $4 \mathbf{k}, \mathbf{5 c}, \mathbf{5 d}$, and $\mathbf{5 e}(\mathrm{CAM}-\mathrm{B} 3 \mathrm{LYP} / 6-311++\mathrm{G}(\mathrm{d}, \mathrm{p})$; PCM: $\mathrm{CH}_{2} \mathrm{Cl}_{2}$ ).

\begin{tabular}{|c|c|c|c|}
\hline Compound & $\begin{array}{c}\text { Experimental } \lambda_{\text {max,abs }}(\mathrm{nm}) \\
\left(\varepsilon\left(\mathrm{M}^{-1} \mathrm{~cm}^{-1}\right)\right)\end{array}$ & $\begin{array}{l}\text { Calculated } \lambda_{\text {max,abs }}(\mathrm{nm}) \\
\text { (Oscillatory Strength) }\end{array}$ & Most Dominant Contributions \\
\hline $4 k$ & $294(66,000)$ & $285(2.187)$ & $\begin{array}{l}\text { HOMO-1 } \rightarrow \text { LUMO }(65 \%) \\
\text { HOMO } \rightarrow \text { LUMO+1 }(27 \%)\end{array}$ \\
\hline $5 c$ & $311(40,000)$ & $302(1.436)$ & $\begin{array}{c}\mathrm{HOMO} \rightarrow \mathrm{LUMO}(67 \%) \\
\mathrm{HOMO} \rightarrow \mathrm{LUMO}+1(20 \%)\end{array}$ \\
\hline $5 d$ & $311(45,100)$ & $303(1.496)$ & $\begin{array}{c}\mathrm{HOMO} \rightarrow \mathrm{LUMO}(37 \%) \\
\mathrm{HOMO} \rightarrow \mathrm{LUMO}+1(50 \%)\end{array}$ \\
\hline $5 e$ & $356(34,100)$ & $333(2.187)$ & $\begin{array}{c}\mathrm{HOMO} \rightarrow \mathrm{LUMO}(30 \%) \\
\mathrm{HOMO} \rightarrow \mathrm{LUMO}+1(54 \%)\end{array}$ \\
\hline
\end{tabular}

According to TD-DFT calculations, the longest wavelength absorption bands of compounds $5 c$, $\mathbf{5 d}$, and $\mathbf{5 e}$, possess dominant contributions of $\mathrm{HOMO} \rightarrow \mathrm{LUMO}$ and $\mathrm{HOMO} \rightarrow \mathrm{LUMO}+1$ transitions. It is noteworthy that compound $\mathbf{4 k}$ does not involve the HOMO $\rightarrow$ LUMO transition as a constituent of the longest wavelength absorption band. The calculated electronic structure reveals that the longest wavelength absorption band consists of dominant contributions of HOMO-1 $\rightarrow$ LUMO and $\mathrm{HOMO} \rightarrow \mathrm{LUMO}+1$ transitions, which both reveal local excitation character at higher energies 
in the $p$-cyano biphenyl oxazole part (HOMO- $\rightarrow$ LUMO) and in the $p$-anisyl isoxazole moiety $(\mathrm{HOMO} \rightarrow \mathrm{LUMO}+1)$ (Figure 6, left). The relative contribution of the HOMO $\rightarrow$ LUMO transition decreases gradually from $\mathbf{5 c}$ to $5 \mathrm{e}$, possibly caused by diminished orbital overlap due to increasing charge-transfer character. With increasing acceptor strength, the amount of the HOMO $\rightarrow \mathrm{LUMO}+1$, representing charge transfer transition over the complete molecule, steadily increases. The HOMO $\rightarrow$ LUMO, also charge transfer in its nature, only possesses a moderate overlap in the central isoxazole. Expectedly, stronger acceptor substituents attenuate the central overlap on the isoxazole, and, consequently, the $\mathrm{HOMO} \rightarrow \mathrm{LUMO}+1$ transition prevails (Figure 6, right).

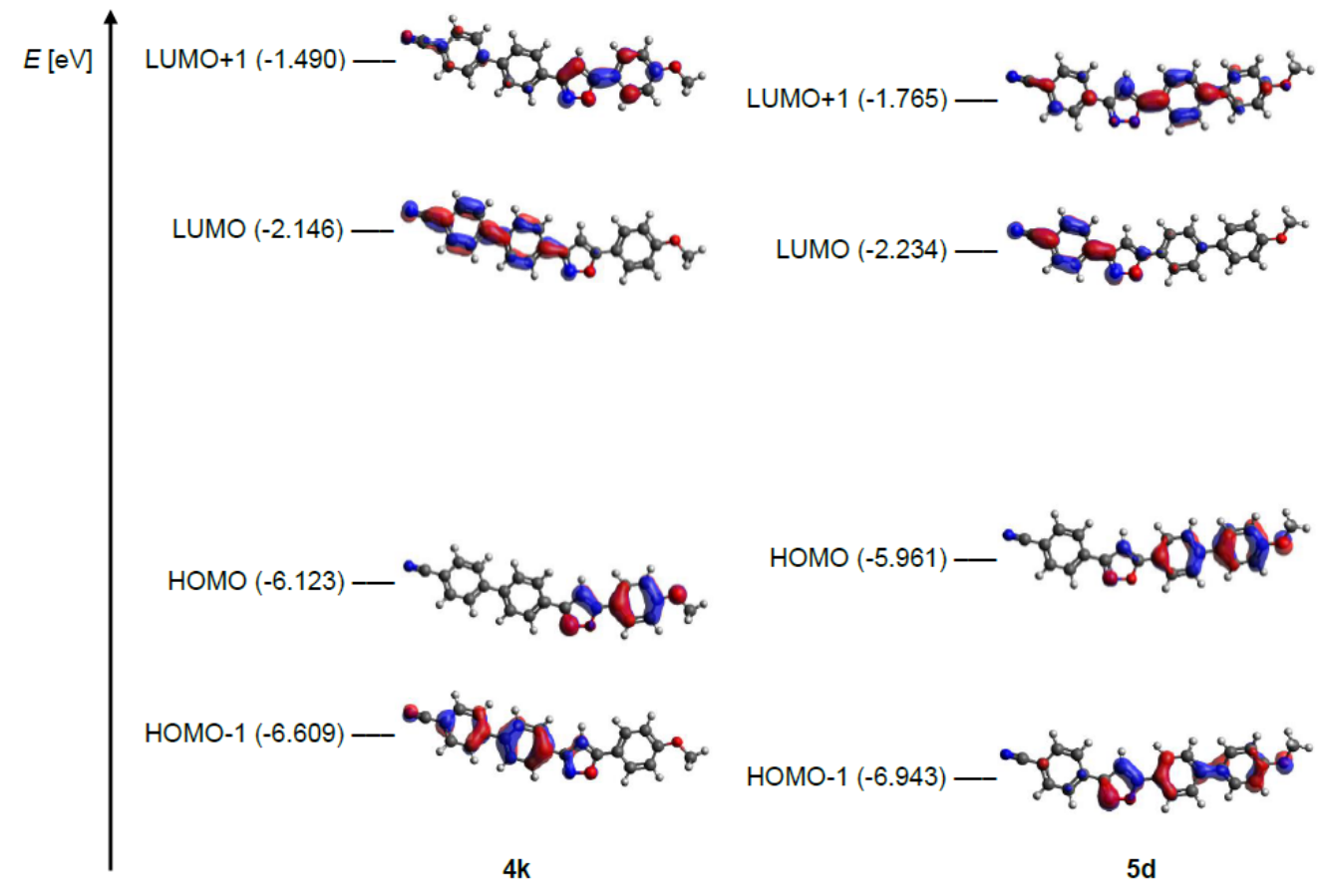

Figure 6. Comparison of selected DFT-computed Kohn-Sham frontier molecular orbitals and corresponding orbital energies between compounds 4k (left) and 5d (right) (B3LYP/6-311G(d,p); PCM: $\mathrm{CH}_{2} \mathrm{Cl}_{2}$ ).

This behavior can be additionally quantified by coefficient density analysis of the corresponding DFT data for ground state optimization using Multiwfn (Table 7) [54]. The distance between coefficient density focal points of $\mathrm{HOMO}$ and $\mathrm{LUMO}, d_{\mathrm{FMO}}$, increases from structure $\mathbf{5 c}$ to $\mathbf{5 d}$, while the overlap integral of $\mathrm{HOMO}$ and LUMO, $<\mathrm{HOMO} \mid \mathrm{LUMO}>$, gradually decreases. The distinct charge transfer character of $5 \mathbf{e}$ in comparison to $5 \mathbf{c}$ can be illustrated by HOMO-LUMO difference plots (Figure 7).

Table 7. Coefficient density analysis of 5c-e carried out with Multiwfn [54].

\begin{tabular}{cccc}
\hline Compound & $d_{\text {FMO }}(\AA)$ & <HOMO|LUMO & HOMO $\rightarrow$ LUMO (\%) \\
\hline $5 \mathrm{c}$ & 6.143 & 0.541 & 67 \\
\hline $5 \mathrm{~d}$ & 9.005 & 0.338 & 37 \\
\hline $\mathbf{5 e}$ & 11.136 & 0.221 & 30 \\
\hline
\end{tabular}
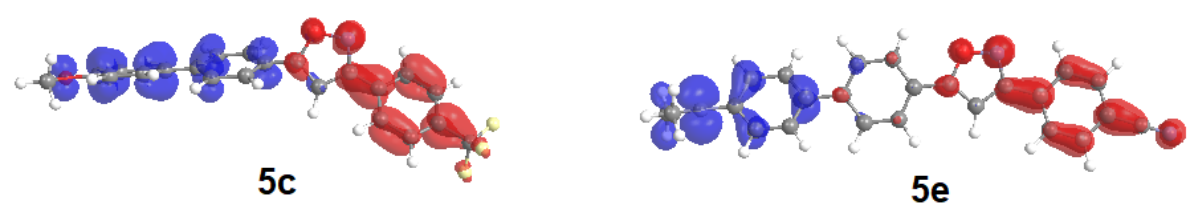

Figure 7. Comparison of HOMO-LUMO difference plots between isoxazoles $5 \mathrm{c}(\mathbf{l e f t})$ and $5 \mathbf{e}$ (right). 
A conclusion from the study of the electronic structures is that the 5-biaryl-substituted isoxazoles 5 are better suited for fine-tuning of the absorption and emission properties over a broad part of the spectrum. With the highly emissive compound $\mathbf{5 c}$ as a model system, the optimized geometry of the vibrationally relaxed excited state $\left(\mathrm{S}_{1}\right)$ was calculated with Gaussian09, employing the same functional and basis set as for ground state optimization in dichloromethane. Via TD-DFT, the emission from $\mathrm{S}_{1}$ to the Franck-Condon state $\mathrm{S}_{0}{ }^{\mathrm{FC} 2}$ was calculated. In addition to the optimization of $\mathrm{S}_{0}$ and excitation to $\mathrm{S}_{1}{ }^{\mathrm{FC} 1}$, the whole excitation-emission cycle of $\mathbf{5 c}$ could be computationally simulated (Figure 8 ). The computed emission maximum $\lambda_{\text {max,em,DFT }}=361 \mathrm{~nm}$ is in good agreement with the experiment $\left(\lambda_{\text {max,em,exp }}=376 \mathrm{~nm}\right)$. It is noticeable that the geometry of the $S_{1}$ is essentially planarized compared to the equilibrium geometry of $\mathrm{S}_{0}$.

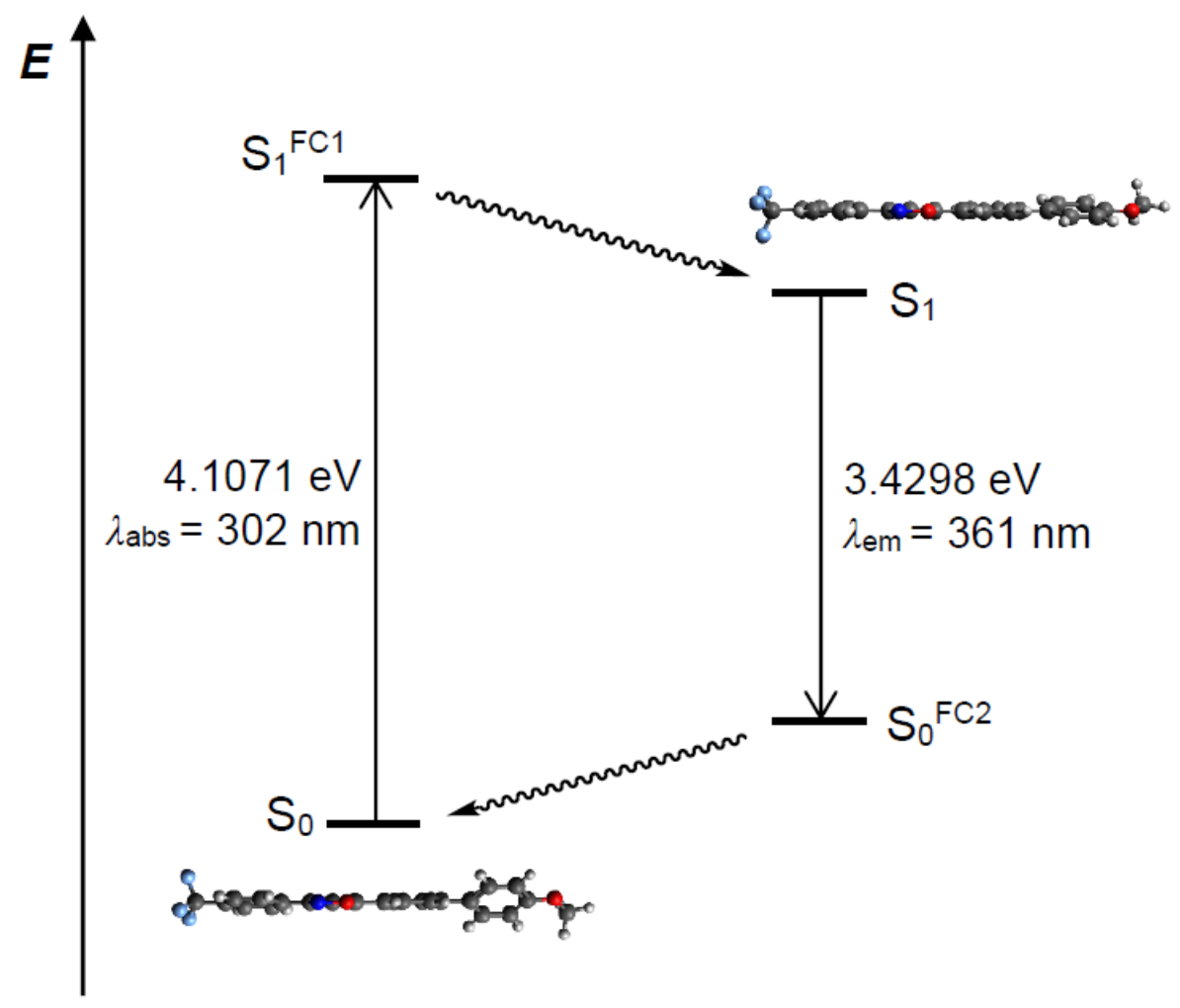

Figure 8. Computed results for excitation to the Franck-Condon state $S_{1}{ }^{F C 1}$, vibrational relaxation to $S_{1}$, emission to Franck-Condon state $\mathrm{S}_{0}{ }^{\mathrm{FC} 2}$ and relaxation to $\mathrm{S}_{0}$ of compound $5 \mathrm{c}$. Geometry optimization of $\mathrm{S}_{0} / \mathrm{S}_{1}$ : B3LYP/6-311G(d,p), PCM: $\mathrm{CH}_{2} \mathrm{Cl}_{2}$; absorption/emission: CAM-B3LYP/6-311++G(d,p); PCM: $\mathrm{CH}_{2} \mathrm{Cl}_{2}$.

\section{Conclusions}

A concise consecutive four-component synthesis of novel biaryl-substituted isoxazoles was successfully established. Interestingly, the palladium catalyst can be employed sequentially for both Sonogashira coupling and Suzuki coupling without addition of further catalyst. The one-pot process is intercepted by a regioselective cyclocondensation of the initially formed alkynone with hydroxyl amine. Selected derivatives with a donor-acceptor substitution pattern display pronounced fluorescence in solution and remarkably high relative fluorescence quantum yields in most cases, a property which has been scarcely described for isoxazoles. In a consanguineous series of 5-biaryl-substituted isoxazoles with increasing donor and acceptor strengths, the tunability of Stokes shift between 5600 to $10,000 \mathrm{~cm}^{-1}$ (sic!) can be impressively shown. The same compounds are also emissive in the solid state, though with rather low fluorescence quantum yields. Quantum chemical calculations plausibly rationalize the electronic properties in good agreement with the experimental results. These novel biaryl-substituted isoxazoles are intensively emissive in nonpolar environments and are therefore perfectly suited for 
developing lipophilic luminophores for biophysical application. Studies to incorporate biaryl oxazole luminophores into polystyrene particles and ligating them to biologically interesting lipophilic targets, such as bilayer membranes, are currently underway.

Supplementary Materials: The following are available online at http://www.mdpi.com/2073-4344/10/12/1412/s1, Figure S1: Normalized emission spectra of $5 \mathrm{c}$ in toluene, $\mathrm{CH}_{2} \mathrm{Cl}_{2}$ and $\mathrm{MeCN}$ (recorded at $293 \mathrm{~K}, \lambda_{\mathrm{exc}}=\lambda_{\text {max,abs }}$ ), Figure S2: Normalized emission spectra of $5 \mathrm{~d}$ in toluene, $\mathrm{CH}_{2} \mathrm{Cl}_{2}$ and $\mathrm{MeCN}$ (recorded at $293 \mathrm{~K}$, $\lambda_{\text {exc }}=\lambda_{\text {max,abs }}$ ), Figure S3: Asymmetric unit of isoxazole $4 \mathrm{k}$ (thermal ellipsoids shown at 50\% probability), Figure S4: Hirshfeld surface of isoxazole $4 \mathrm{k}$ in the crystal lattice mapped with the $\mathrm{d}_{\text {norm }}$ property. Red represents the closest, blue the most distant contacts, Figure S5: Optimized ground state geometry of 4k (B3LYP/6-311G(d,p), $\mathrm{PCM} \mathrm{CH} \mathrm{Cl}_{2}$ ), Figure S6: Optimized ground state geometry of 5c (B3LYP/6-311G(d,p), $\left.\mathrm{PCM} \mathrm{CH}_{2} \mathrm{Cl}_{2}\right)$, Figure S7:

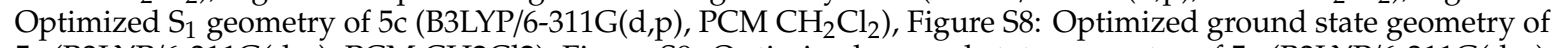
5c (B3LYP/6-311G(d,p), PCM CH2Cl2), Figure S9: Optimized ground state geometry of 5e (B3LYP/6-311G(d,p), PCM CH $\mathrm{Cl}_{2}$ ), Table S1: Experimental details for the synthesis of 3-biarylsubstituted isoxazoles, Table S2. Experimental details for the synthesis of 5-biarylsubstituted isoxazoles, Table S3: Solvent-dependent emission of compounds $5 \mathrm{c}$ and $5 \mathrm{~d}$ (recorded at $293 \mathrm{~K}, c_{0}(5)=10^{-6} \mathrm{M}, \lambda_{\mathrm{exc}}=\lambda_{\max , \text { abs }}$ ). General information on the experimental procedures and analytics; general procedures for the one-pot syntheses and analytical data of 3-biaryl-substituted isoxazoles 4 and 5-biaryl-substituted isoxazoles 5, 1H and 13C NMR spectra of compounds 4 and 5, crystal data and structure refinement for compound $4 \mathrm{k}$, data of quantum chemical calculations on selected structures $4 \mathrm{l}, 5 \mathrm{c}, 5 \mathrm{~d}$, and $5 \mathrm{e}$.

Author Contributions: The work is part of the Ph. D. thesis of T.D., which was supervised by T.J.J.M. The conceptualization was outlined and accompanied by T.J.J.M. Synthetic studies, analytical assignments, and photophysical investigations were performed by T.D., who compiled and interpreted the obtained data. Quantum chemical calculations were performed by L.M. and T.D., and the crystal structure analysis was carried out and interpreted by G.J.R. Writing of the original draft was done by T.D., and review and editing by T.J.J.M. Project administration and funding acquisition was conducted by T.J.J.M. All authors have read and agreed to the published version of the manuscript.

Funding: This research was funded by Jürgen-Manchot-Stiftung Düsseldorf (scholarship for T.D.), and by Fonds der Chemischen Industrie (scholarship for L.M. and ad personam support for T.J.J.M.).

Acknowledgments: The authors cordially thank the Jürgen-Manchot-Stiftung Düsseldorf and Fonds der Chemischen Industrie for financial support. Computational infrastructure and support were provided by the Centre for Information and Media Technology at Heinrich Heine University Düsseldorf.

Conflicts of Interest: The authors declare no conflict of interest. The funders had no role in the design of the study, in the collection, analyses, or interpretation of data, in the writing of the manuscript, or in the decision to publish the results.

\section{References and Note}

1. Rajanarendar, E.; Rama Krishna, S.; Nagaraju, D.; Govardhan Reddy, K.; Kishore, B.; Reddy, Y.N. Environmentally benign synthesis, molecular properties prediction and anti-inflammatory activity of novel isoxazolo[5,4-d]isoxazol-3-yl-aryl-methanones via vinylogous Henry nitroaldol adducts as synthons. Bioorg. Med. Chem. Lett. 2015, 25, 1630-1634. [CrossRef]

2. Banoglu, E.; Çelikoglu, E.; Volker, S.; Olgac, A.; Gerstmeier, J.; Garscha, U.; Caliskan, B.; Schubert, U.S.; Carotti, A.; Macchiarulo, A.; et al. 4,5-Diarylisoxazol-3-carboxylic acids: A new class of leukotriene biosynthesis inhibitors potentially targeting 5-lipoxygenaseactivating protein (FLAP). Eur. J. Med. Chem. 2016, 113, 1-10. [CrossRef]

3. Siddiqui, N.; Idrees, M.; Khati, N.T.; Dhonde, M.G. Synthesis and antimicrobial activities of some new pyrazoles, oxadiazoles and isoxazole bearing benzofuran moiety. S. Afr. J. Chem. 2013, 66, 248-253.

4. Basha, S.S.; Divya, K.; Padmaja, A.; Padmavathi, V. Synthesis and antimicrobial activity of thiazolyl pyrazoles and isoxazoles. Res. Chem. Intermed. 2015, 41, 10067-10083. [CrossRef]

5. Lee, Y.S.; Park, S.M.; Kim, B.H. Synthesis of 5-isoxazol-5-yl-2'-deoxyuridines exhibiting antiviral activity against HSV and several RNA viruses. Bioorg. Med. Chem. Lett. 2009, 19, 1126-1128. [CrossRef]

6. Kumbhare, R.M.; Kosurkar, U.B.; Janaki Ramaiah, M.; Dadmal, T.L.; Pushpavalli, S.N.C.V.L.; Pal-Bhadra, M. Synthesis and biological evaluation of novel triazoles and isoxazoles linked 2-phenyl benzothiazole as potential anticancer agents. Bioorg. Med. Chem. Lett. 2012, 22, 5424-5427. [CrossRef] 
7. Tzanetou, E.; Liekens, S.; Kasiotis, K.M.; Melagraki, G.; Afantitis, A.; Fokialakis, N.; Haroutounian, S.A. Antiproliferative novel isoxazoles: Modeling, virtual screening, synthesis, and bioactivity evaluation. Eur. J. Med. Chem. 2014, 81, 139-149. [CrossRef]

8. Pairas, G.N.; Perperopoulou, F.; Tsoungas, P.G.; Varvounis, G. The Isoxazole Ring and Its N-Oxide: A Privileged Core Structure in Neuropsychiatric Therapeutics. ChemMedChem 2017, 12, 408-419. [CrossRef]

9. Lamberth, C. Oxazole and Isoxazole Chemistry in Crop Protection. J. Heterocycl. Chem. 2018, 55, 2035-2045. [CrossRef]

10. Sato, K.; Kawasaki, A.; Karuo, Y.; Tarui, A.; Kawai, K.; Omote, M. Synthesis of new fluorescent molecules having an aggregation-induced emission property derived from 4-fluoroisoxazoles. Beilstein J. Org. Chem. 2020, 16, 1411-1417. [CrossRef]

11. de Brito, A.C.F.; Correa, R.S.; Pinto, A.A.; Matos, M.J.S.; Tenorio, J.C.; Taylor, J.G.; Cazati, T. Synthesis, crystal structure, photophysical properties and theoretical studies of a novel bis(phenylisoxazolyl) benzene derivative. J. Mol. Struct. 2018, 1163, 197-204. [CrossRef]

12. Irfan, A.; Al-Sehemi, A.G.; Chaudhry, A.R.; Muhammad, S. A first-principles study of the linear and nonlinear optical properties of isoxazole derivatives. J. Theor. Comput. Chem. 2016, 15, 1650060. [CrossRef]

13. Morita, T.; Yugandar, S.; Fuse, S.; Nakamura, H. Recent progresses in the synthesis of functionalized isoxazoles. Tetrahedron Lett. 2018, 59, 1159-1171. [CrossRef]

14. Hu, F.; Szostak, M. Recent Developments in the Synthesis and Reactivity of Isoxazoles: Metal Catalysis and Beyond. Adv. Synth. Catal. 2015, 357, 2583-2614. [CrossRef]

15. Chen, Y.; Li, L.; He, X.; Li, Z. Four-Component Reactions for the Synthesis of Perfluoroalkyl Isoxazoles. ACS Catal. 2019, 9, 9098-9102. [CrossRef]

16. Thirukovela, N.S.; Balaboina, R.; Botla, V.; Vadde, R. One-pot regioselective synthesis of substituted pyrazoles and isoxazoles in PEG-400/water medium by $\mathrm{Cu}$-free nano-Pd catalyzed sequential acyl Sonogashira coupling-intramolecular cyclization. Catal. Sci. Technol. 2019, 9, 6471-6481. [CrossRef]

17. Wang, X.-D.; Zhu, L.-H.; Liu, P.; Wang, X.-Y.; Yuan, H.-Y.; Zhao, Y.-L. Copper-Catalyzed Cascade Cyclization Reactions of Diazo Compounds with tert-Butyl Nitrite and Alkynes: One-Pot Synthesis of Isoxazoles. J. Org. Chem. 2019, 84, 16214-16221. [CrossRef]

18. Liu, H.; Geng, Z.; Zhang, S.; Han, J. One-pot three-component synthesis of 3,5-disubstituted isoxazoles by a coupling-cyclocondensation sequence. Heterocycles 2014, 89, 1221-1227. [CrossRef]

19. Willy, B.; Rominger, F.; Müller, T.J.J. Novel Microwave-Assisted One-Pot Synthesis of Isoxazoles by a Three-Component Coupling-Cycloaddition Sequence. Synthesis 2008, 293-303. [CrossRef]

20. Hu, X.-M.; Dong, H.; Li, Y.-D.; Huang, P.; Tiana, Z.; Wang, P.-A. Tandem grinding reactions involving aldol condensation and Michael addition in sequence for synthesis of 3,4,5-trisubstituted isoxazoles. RSC Adv. 2019, 9, 27883-27887. [CrossRef]

21. Gayon, E.; Quinonero, O.; Lemouzy, S.; Vrancken, E.; Campagne, J.M. Transition-Metal-Catalyzed Uninterrupted Four-Step Sequence to Access Trisubstituted Isoxazoles. Org. Lett. 2011, 13, 6418-6421. [CrossRef]

22. Berlham, I.B. On an Empirical Correlation between Nuclear Conformation and Certain Fluorescence and Absorption Characteristics of Aromatic Compounds. J. Phys. Chem. 1970, 74, 3085-3093. [CrossRef]

23. Im, H.S.; Bernstein, E.R. Geometry and torsional motion of biphenyl in the ground and first excited singlet state. J. Chem. Phys. 1988, 88, 7337-7347. [CrossRef]

24. McFarland, S.A.; Finney, N.S. Fluorescent chemosensors based on conformational restriction of a biaryl fluorophore. J. Am. Chem. Soc. 2001, 123, 1260-1261. [CrossRef]

25. May, L.; Daniel, S.; Müller, T.J.J. Diversity-oriented approach to functional thiophene dyes by Suzuki coupling-lithiation one-pot sequences. Org. Chem. Front. 2020, 7, 329-339. [CrossRef]

26. Dohe, J.; Koßmann, J.; Müller, T.J.J. Diversity-oriented four-component synthesis of solid state luminescent difluoro oxazaborinines. Dyes Pigments 2018, 157, 198-217. [CrossRef]

27. Burke, M.D.; Schreiber, S.L. A planning strategy for diversity-oriented synthesis. Angew. Chem. Int. Ed. 2004, 43, 46-58. [CrossRef]

28. Denißen, M.; Nordmann, J.; Dziambor, J.; Mayer, B.; Frank, W.; Müller, T.J.J. Sequential palladium catalyzed coupling-cyclocondensation-coupling (C3) four-component synthesis of intensively blue luminescent biaryl substituted pyrazoles. RSC Adv. 2015, 5, 33838-33854. [CrossRef] 
29. Lessing, T.; Müller, T.J.J. Sequentially Palladium-Catalyzed Processes in One-Pot Syntheses of Heterocycles. Appl. Sci. 2015, 5, 1803-1836. [CrossRef]

30. Müller, T.J.J. Sequential Catalysis Involving Metal Catalyzed Cycloisomerizations and Cyclizations. In Molecular Catalysts: Structure and Functional Design; Gade, L.H., Hofmann, P., Eds.; Wiley-VCH Verlag GmbH \& Co. KGaA: Weinheim, Germany, 2014; pp. 255-279.

31. Müller, T.J.J. Sequentially Palladium-Catalyzed Processes. Top. Organomet. Chem. 2006, 19, 149-205. [CrossRef]

32. Gers-Panther, C.F.; Müller, T.J.J. Multicomponent syntheses of heterocycles initiated by catalytic generation of ynones and ynediones. Adv. Heterocycl. Chem. 2016, 120, 67-98. [CrossRef]

33. Crystallographic data (excluding structure factors) for the structure reported in this paper have been deposited with the Cambridge Crystallographic Data Centre as supplementary publication no. CCDC 2032844 (4k). Copies of the data can be obtained free of charge on application to CCDC, 12 Union Road, Cambridge CB2 1EZ, UK.

34. Turner, M.J.; McKinnon, J.J.; Wolff, S.K.; Grimwood, D.J.; Spackman, P.R.; Jayatilaka, D.; Spackman, M.A. CrystalExplorer17, Version 17.5; University of Western Australia: Perth, Australia, 2017; Available online: http://hirshfeldsurface.net (accessed on 4 November 2020).

35. McKinnon, J.J.; Spackman, M.A.; Mitchell, A.S. Novel tools for visualizing and exploring intermolecular interactions in molecular crystals. Acta Cryst. 2004, 60, 627-668. [CrossRef] [PubMed]

36. Spackman, M.A.; McKinnon, J.J. Fingerprinting intermolecular interactions in molecular crystals. Cryst. Eng. Commun. 2002, 4, 378-392. [CrossRef]

37. McKinnon, J.J.; Jayatilaka, D.; Spackman, M.A. Towards quantitative analysis of intermolecular interactions with Hirshfeld surfaces. Chem. Commun. 2007, 37, 3814-3816. [CrossRef] [PubMed]

38. Qin, N.W.; Basarić, N.; Hofkens, J.; Ameloot, M.; Pouget, J.; Lefèvre, J.-P.; Valeur, B.; Gratton, E.; van de Ven, M.; Silva, N.D., Jr.; et al. Fluorescence Lifetime Standards for Time and Frequency Domain Fluorescence Spectroscopy. Anal. Chem. 2007, 79, 2137-2149. [CrossRef]

39. Reynolds, G.A.; Drexhage, K.H. New coumarin dyes with rigidized structure for flashlamp-pumped dye lasers. Opt. Commun. 1975, 13, 222-225. [CrossRef]

40. Jortner, J. Radiationless transitions. Pure Appl. Chem. 1971, 27, 389-420. [CrossRef]

41. Frisch, M.J.; Trucks, G.W.; Schlegel, H.B.; Scuseria, G.E.; Robb, M.A.; Cheeseman, J.R.; Scalmani, G.; Barone, V.; Mennucci, B.; Petersson, G.A. Gaussian 09; Gaussian, Inc.: Wallingford, CT, USA, 2009.

42. Lee, C.; Yang, W.; Parr, R.G. Development of the Colle-Salvetti correlation-energy formula into a functional of the electron density. Phys. Rev. B 1988, 37, 785-789. [CrossRef]

43. Becke, A.D. A new mixing of Hartree-Fock and local density-functional theories. J. Chem. Phys. 1993, 98, 1372-1377. [CrossRef]

44. Becke, A.D. Density-functional thermochemistry. III. The role of exact exchange. J. Chem. Phys. 1993, 98, 5648-5652. [CrossRef]

45. Kim, K.; Jordan, K.D. Comparison of Density Functional and MP2 Calculations on the Water Monomer and Dimer. J. Phys. Chem. 1994, 98, 10089-10094. [CrossRef]

46. Stephens, P.J.; Devlin, F.J.; Chabalowski, C.F.; Frisch, M.J. Ab Initio Calculation of Vibrational Absorption and Circular Dichroism Spectra Using Density Functional Force Fields. J. Phys. Chem. 1994, 98, 11623-11627. [CrossRef]

47. Krishnan, R.; Binkley, J.S.; Seeger, R.; Pople, J.A. Self-consistent molecular orbital methods. XX. A basis set for correlated wave functions. J. Chem. Phys. 1980, 72, 650-654. [CrossRef]

48. Scalmani, G.; Frisch, M.J. Continuous surface charge polarizable continuum models of solvation. I. General formalism. J. Chem. Phys. 2010, 132, 114110. [CrossRef] [PubMed]

49. Akiyama, M.; Watanabe, T.; Kakihana, M. Internal Rotation of Biphenyl in Solution Studied by IR an NMR Spectra. J. Phys. Chem. 1986, 90, 1752-1755. [CrossRef]

50. Bauernschmitt, R.; Ahlrichs, R. Treatment of electronic excitations within the adiabatic approximation of time dependent density functional theory. Chem. Phys. Lett. 1996, 256, 454-464. [CrossRef]

51. Casida, M.E.; Jamorski, C.; Casida, K.C.; Salahub, D.R. Molecular excitation energies to high-lying bound states from time-dependent density-functional response theory: Characterization and correction of the time-dependent local density approximation ionization threshold. J. Chem. Phys. 1998, 108, 4439-4449. [CrossRef]

52. Stratmann, R.E.; Scuseria, G.E.; Frisch, M.J. An efficient implementation of time-dependent density-functional theory for the calculation of excitation energies of large molecules. J. Chem. Phys. 1998, 109, 8218-8224. [CrossRef] 
53. Yanai, T.; Tew, D.P.; Handy, N.C. A new hybrid exchange-correlation functional using the Coulomb-attenuating method (CAM-B3LYP). Chem. Phys. Lett. 2004, 393, 51-57. [CrossRef]

54. Lu, T.; Chen, F. Multiwfn: A multifunctional wavefunction analyzer. J. Comput. Chem. 2012, 33, 580-592. [CrossRef] [PubMed]

Sample Availability: Samples of the compounds $\mathbf{4 f}, \mathbf{4 g}$, and $5 \mathbf{e}$ are available from the authors.

Publisher's Note: MDPI stays neutral with regard to jurisdictional claims in published maps and institutional affiliations.

(C) 2020 by the authors. Licensee MDPI, Basel, Switzerland. This article is an open access article distributed under the terms and conditions of the Creative Commons Attribution (CC BY) license (http://creativecommons.org/licenses/by/4.0/). 